\title{
The extent, characteristics and potential of solar powered irrigation systems in South Africa
}

\author{
P. Piliso' ${ }^{1}$ (D) A.Senzanje ${ }^{1}$ (D), K. Dhavu² \\ 1. University of KwaZulu-Natal, Pietermaritzburg, South Africa \\ 2. Agricultural Research Council, Pretoria, South Africa
}

\begin{abstract}
South Africa has been identified as having a high potential for solar powered irrigation. However, there has been a lag in the development of solar powered irrigation systems (SPIS) there, mainly due to the high investment cost associated with solar technology. South Africa has frequently implemented load shedding, which has affected many farmers. The work reported in this paper sought to determine the extent of solar powered irrigation and characteristics of the system types in use. The extent of SPIS in South Africa was determined using a questionnaire, and categorised in terms of farm size, SPIS configuration (storage of energy), type of irrigation, and location of the system. These were established mainly from a literature search. The questionnaires were administered on Survey Monkey ${ }^{\circledR}$. The sample size of the study was 138755 potential respondents. The number that participated and completed the questionnaires included a total of 18 SPIS engineers, installers and designers and 13 SPIS users (farmers). The main problem encountered with the distribution of the survey was finding SPIS users to participate. Results from SPIS engineers, installers and designers showed that most SPIS they implemented were in the Western Cape and the Eastern Cape, at 33\% of the responses for both provinces. The total area under SPIS was found to be $364 \mathrm{ha}$, while the area under irrigation is South Africa is 130000 ha, indicating a high potential for SPIS development. Some details on the extent of SPIS in South Africa were determined in this paper, but more SPIS users need to be identified to determine the details of their SPIS.
\end{abstract}

Keywords: solar panels, irrigation system integration, water use efficiency, load shedding

\section{Highlights}

- $\quad 44 \%$ of the SPIS engineers, installers, and designers implemented SPIS for smallholder farming.

- Drip and sprinkler irrigation are equally the most integrated with SPIS (38\%).

- $\quad$ The water source mostly used with SPIS is a borehole (61\%).

- $\quad 77 \%$ of the SPIS user respondents stated that they have poly-crystalline solar panels.

Journal of Energy in Southern Africa 32(2): 26-40

DOI: https://dx.doi.org/10.17159/2413-3051/2021/v32i2a9045

Published by the University of Cape Town ISSN: 2413-3051 https://journals.assaf.org.za/jesa

This work is licensed under a Creative Commons Attribution-ShareAlike 4.0 International Licence

Sponsored by the Department of Science and Innovation

Corresponding author: Tel.: +27 (0)76 621 4714; email: piwevp@gmail.com cell number 


\section{Introduction}

South Africa has a high potential for solar powered irrigation, as it receives high levels of direct normal irradiation. In the agricultural sector, irrigation is a major consumer of electricity (DoE, 2012). The production of electrical energy through solar photovoltaic (PV) panels is one of the most environmentally friendly, emission free and sustainable sources of energy known. However, the main source of electrical power in South Africa remains fossil fuels, with most of its electrical power produced by coal-fired power stations.

South Africa's electricity costs were once among the cheapest in the world. This was before 2008 when Eskom, the country's energy supplier, had trouble meeting the country's electricity demands (Jumman and Lecler, 2010). This was the result of the infrastructure, at the time, not matching the maintenance requirements and the growth demands of the country. The result was a decline in service, the introduction of 'load shedding' and an increase in electricity tariffs. A 25\% tariff increase effective from 2010 and for each of the following three years was approved. The economic state of the country, coupled with the tariff increases and load shedding, was set to have a negative impact on farm profitability sustainably (Jumman and Lecler, 2010).

Most of the irrigation infrastructure in South Africa is on commercial farms, where the source of water is highly dependent on surface water resources such as rivers and dams. Commercial farmers are driven by energy efficiency and independence, while smallholder farmers are driven by access to energy and the cost of fuel (Hassan, 2015). According to Hassan (2015), the area of arable land in South Africa that is under solar powered irrigation is estimated to be approximately 2000 hectares. Approximately 1.3 million hectares of land was under irrigation in 2014/2015 according to Bonthuys (2018). Apart from the Hassan report, there is little information and documentation on the extent of solar powered irrigation systems (SPIS) development in South Africa, and the information available is mainly short articles on one SPIS that has been implemented by a company for exposure (Erasmus, 2013; van der Walt 2019). As a result, information and characterisation about SPIS in South Africa is lacking. The main objective of the research reported in this paper was to determine the extent and characteristics of solar powered irrigation in South Africa. All types of SPIS were included in the research.

\section{Materials and methods}

The study was conducted across the whole of South Africa. The following sections describe the tools and procedures used to develop and distribute a questionnaire to determine the extent of SPIS in South Africa. Before developing the questionnaire, an application for ethical clearance was conducted through the Research Office in the University of Kwa-Zulu Natal and approved under Protocol Reference Number HSS/1039/017M.

\subsection{Survey questionnaire}

The questionnaire (see supplementary material) targeted four groups of stakeholders: (i) SPIS users, (ii) engineers, installers and suppliers, (iii) potential SPIS users, and (iv) former SPIS users. Initially, the questionnaire was developed as a MSWord document where there were different sections for each respondent to complete. A questionnaire was selected as the only tool for data collection due to budget and time constraints. Due to the problem encountered of targeted stakeholders not participating in the survey, the approach was changed to an online questionnaire where participants had an option to participate on their desktops or mobile phones. Survey Monkey® (SurveyMonkey, 1999) was used to create and administer the questionnaire online. Survey Monkey is an online application that helps users create and distribute surveys and to collect and analyse the data obtained. Two questionnaires were designed - one for SPIS engineers, designers and installers, the other for SPIS users and farmers. A pilot test was not conducted, as the sample size was unknown before the questionnaire was distributed, but the aim was to capture all possible stakeholders involved in SPIS.

\subsection{Data collection}

Several approaches were implemented to try obtaining data for the questionnaire from the target stakeholders. Calls were made to practising agricultural engineers working in consulting companies and government departments around South Africa. Requests were made to the South African Irrigation Institute and the South African Institute for Agricultural Engineers to assist in the distribution of the questionnaire by sending out links to the questionnaires to their members. The researcher attended a training programme at Franklin Electric $₫$ where companies that sell Franklin Electric products were in attendance. The links to the questionnaires were sent to Farmer's Weekly magazine, where requests for respondents were posted on the Farmer's Weekly Facebook and Twitter pages. Some followers on both platforms retweeted and shared the requests, which helped spread the requests to a wider audience. Internet searches were conducted to try finding any documentation on systems implemented in South Africa and related contacts. A seminar on SPIS in Pretoria was attended (Maslowaten: 
Large photovoltaic irrigation systems), where networking was done to try finding more participants for the questionnaire. These efforts helped in getting the questionnaire out to the target participants. Key informant interviews and focus group discussions were not done, due to budget and time constraints.

\subsection{Analysis}

The data obtained, which were the responses received from both SPIS engineers, designers and installers and SPIS farmer respondents through Survey Monkey were analysed by Survey Monkey and linked to Microsoft Excel, where tables, pie charts and bar graphs with frequencies of the results obtained were produced. The data was analysed to establish statistics such as most and least common SPIS, highest and least number of SPIS per province, total area covered by SPIS, the most common type of solar panel, etc. Arc GIS was then used to provide a visual presentation of the location of the SPIS systems that were identified through the questionnaire.

\section{Results}

The results presented below are for responses from the SPIS engineers, designers and installers, and the SPIS farmers. Eighteen respondents participated in the SPIS engineers, designers and installers questionnaire and 13 in the SPIS users and farmers.

\subsection{Responses from SPIS engineers, designers and installers}

\subsubsection{Basic demographic information}

The demographics of the SPIS engineers, designers and installers, such as race, gender and age are presented in Table 1 . The age range of the respondents is $25-74$ years, and the dominant age range is $45-$
54 years (29\%); all respondents were male and the majority white. Figure 1 shows the participants' level of education. These ranged from matric to postgraduate degree, with almost half having a postgraduate degree.

\section{Table 1: Demographic profile of respondents}

\begin{tabular}{|c|c|c|}
\hline Categories & $\begin{array}{l}\text { Number of } \\
\text { respondents } \\
\quad(N=18)\end{array}$ & $\begin{array}{c}\text { Total response } \\
\text { rate (\%) }\end{array}$ \\
\hline \multicolumn{3}{|c|}{ Race } \\
\hline White & 13 & 81 \\
\hline African & 2 & 13 \\
\hline Indian & 1 & 6 \\
\hline Coloured & 0 & 0 \\
\hline Other & 0 & 0 \\
\hline Skipped & 2 & - \\
\hline \multicolumn{3}{|c|}{ Gender } \\
\hline Male & 18 & 100 \\
\hline Female & 0 & 0 \\
\hline \multicolumn{3}{|c|}{ Age range (Years) } \\
\hline $18-24$ & 0 & 0 \\
\hline $25-34$ & 4 & 24 \\
\hline $35-44$ & 3 & 18 \\
\hline $45-54$ & 5 & 29 \\
\hline $55-64$ & 4 & 24 \\
\hline $65-74$ & 1 & 6 \\
\hline$>75$ & 0 & 0 \\
\hline Skipped & 1 & - \\
\hline
\end{tabular}

Matric

Diploma

Undergraduate degree

Post- graduate Degree

Other (please specify)

Figure 1: The highest education level achieved by the respondents. 


\subsubsection{Respondents' involvement with SPIS}

Figures 2 to 5 show the involvement of the SPIS engineers, installers and designers with SPIS and their opinion on its potential in South Africa.

Figure 2 shows the range of SPIS each respondent has been involved with. Most are in companies or institutions that have implemented 0-5 SPIS (61\%). Figure 3 shows the type of farming where participants have implemented SPIS. Almost half of the respondents implemented SPIS for smallholder farming. Smallholder farming, as opposed to subsistence farming, is defined as farming which practises both commercial and subsistence farming and the labour force is mainly the family (Cornish, 1998; Gomo, 2010). The respondents were asked about the provinces where they have implemented SPIS. Figure 4 indicates that the respondents who imple- mented SPIS in multiple provinces selected more than one province. The Eastern Cape and the Western Cape have the top SPIS implementation. Figure 5 shows the percentage of irrigation systems mainly integrated with SPIS, and it is evident that sprinkler and drip irrigation had the most integration.

When asked whether the SPIS they implemented had been vandalised or not, $78 \%$ of the respondents replied negatively, and $22 \%$ replied that some of the SPIS had been vandalised.

In response to the question about whether they believe SPIS is feasible in South Africa, most respondents (89\%) answered that they did. Their conclusion is credible since these respondents are the ones involved in the design and implementation of SPIS in South Africa. One of their key implementation activities is to carry out feasibilities.

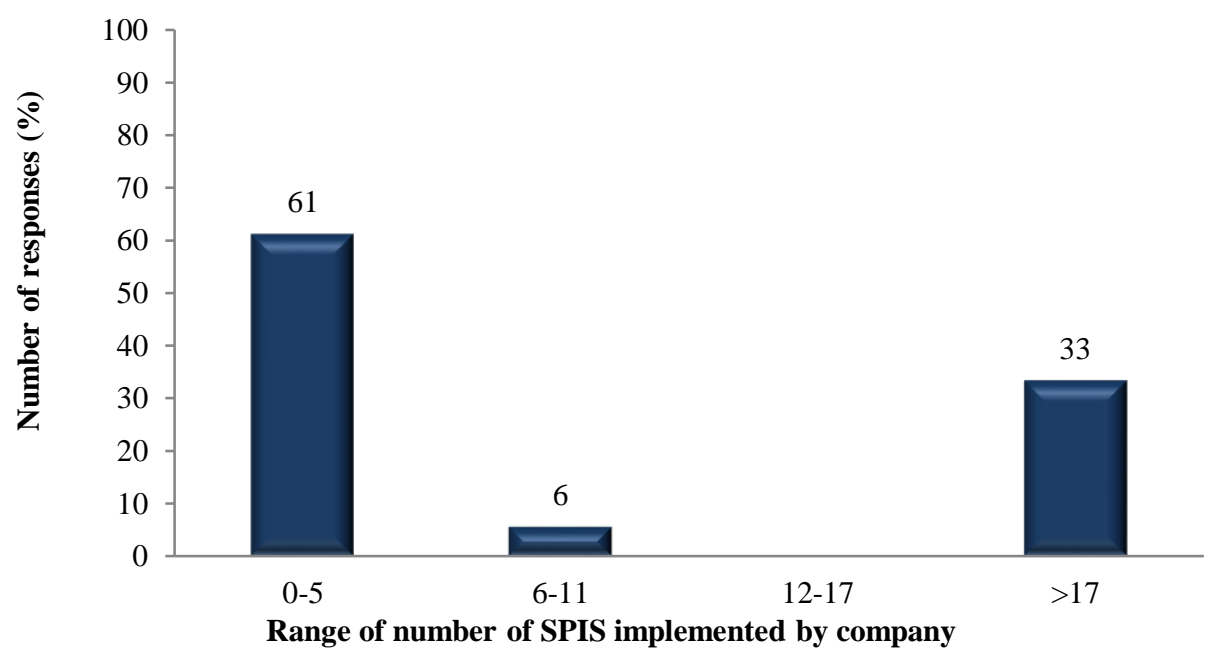

Figure 2: The range of SPIS implemented by the respondents' company or institution.

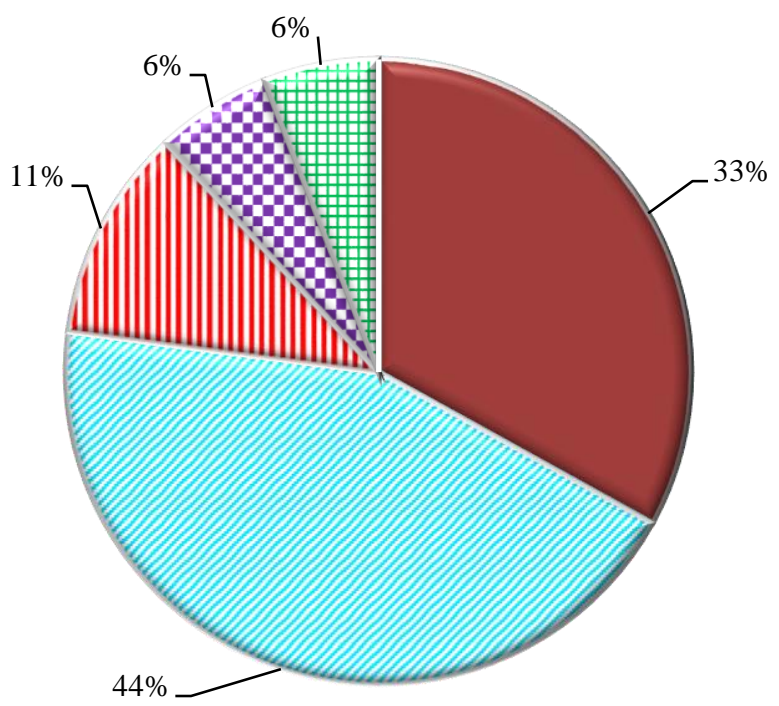

Commerical

Smallholder

Subsistence

Domestic Agricultural Civil

Landscape Irrigation

Figure 3: The main type of farming for which the respondent's company implements SPIS. 


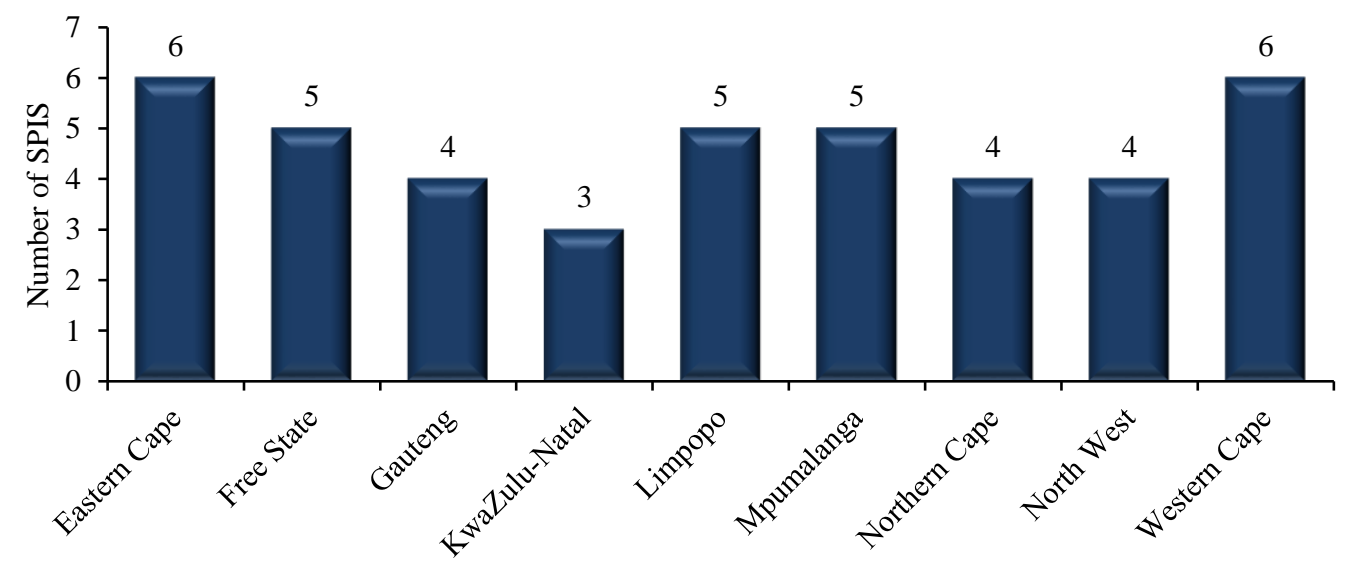

Figure 4: The provinces where the respondents have implemented SPIS.
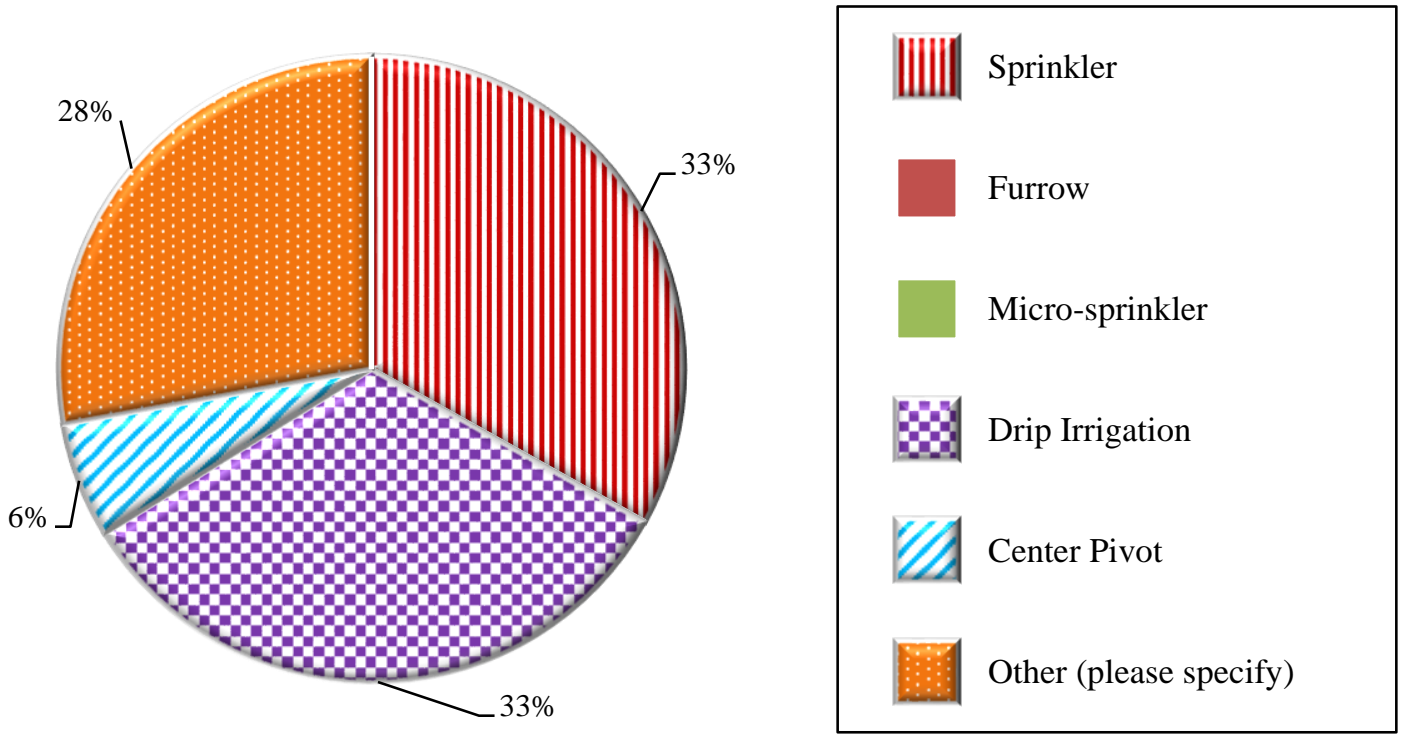

Figure 5: Types of irrigation systems a company mainly implemented.

\subsection{Responses from SPIS users (farmers)}

\subsubsection{Basic SPIS user information}

The demographics of the SPIS users are given in Table 2. Most respondents were white, followed by Africans, and all of them were males. The respondent ages ranged between 25 and 74, with the dominant range being $45-54$.

\section{Table 2: The demographics of the SPIS users}

\begin{tabular}{ccc}
\hline Categories & $\begin{array}{c}\text { No, of respond- } \\
\text { ents }(N=13)\end{array}$ & $\begin{array}{c}\text { Total response } \\
\text { rate }(\%)\end{array}$ \\
\hline Race & \\
White & 10 & 77 \\
African & 3 & 23 \\
Indian & 0 & 0 \\
Coloured & 0 & 0 \\
Other & 0 & 0 \\
\hline
\end{tabular}

\begin{tabular}{ccc}
\hline Categories & $\begin{array}{c}\text { No, of respond- } \\
\text { ents }(N=13)\end{array}$ & $\begin{array}{c}\text { Total response } \\
\text { rate }(\%)\end{array}$ \\
\hline Gender \\
Male & 13 & 100 \\
Female & 0 & 0 \\
\hline & Age & \\
$18-24$ & 0 & 0 \\
$25-34$ & 1 & 9 \\
$35-44$ & 2 & 18 \\
$45-54$ & 8 & 55 \\
$55-64$ & 1 & 9 \\
$65-74$ & 1 & 9 \\
$>75$ & 0 & 0 \\
\hline
\end{tabular}

Figure 6 shows the highest education level obtained by each participant. 


\subsubsection{Location of the SPIS}

The location of the SPIS users, such as the province and district municipality, in which the farm is located, and the area of the farm, is presented in Figure 7 and Table 3. The Western Cape province had the highest number of SPIS (31\%), as shown in Fig- ure 7. Table 3 shows the province, the district municipalities and metropolitans and the size of each farm. The largest SPIS system is in the Western Cape, with a farm size of 140 ha. The smallest SPIS system is in Limpopo, with a farm size of 0.1 ha.
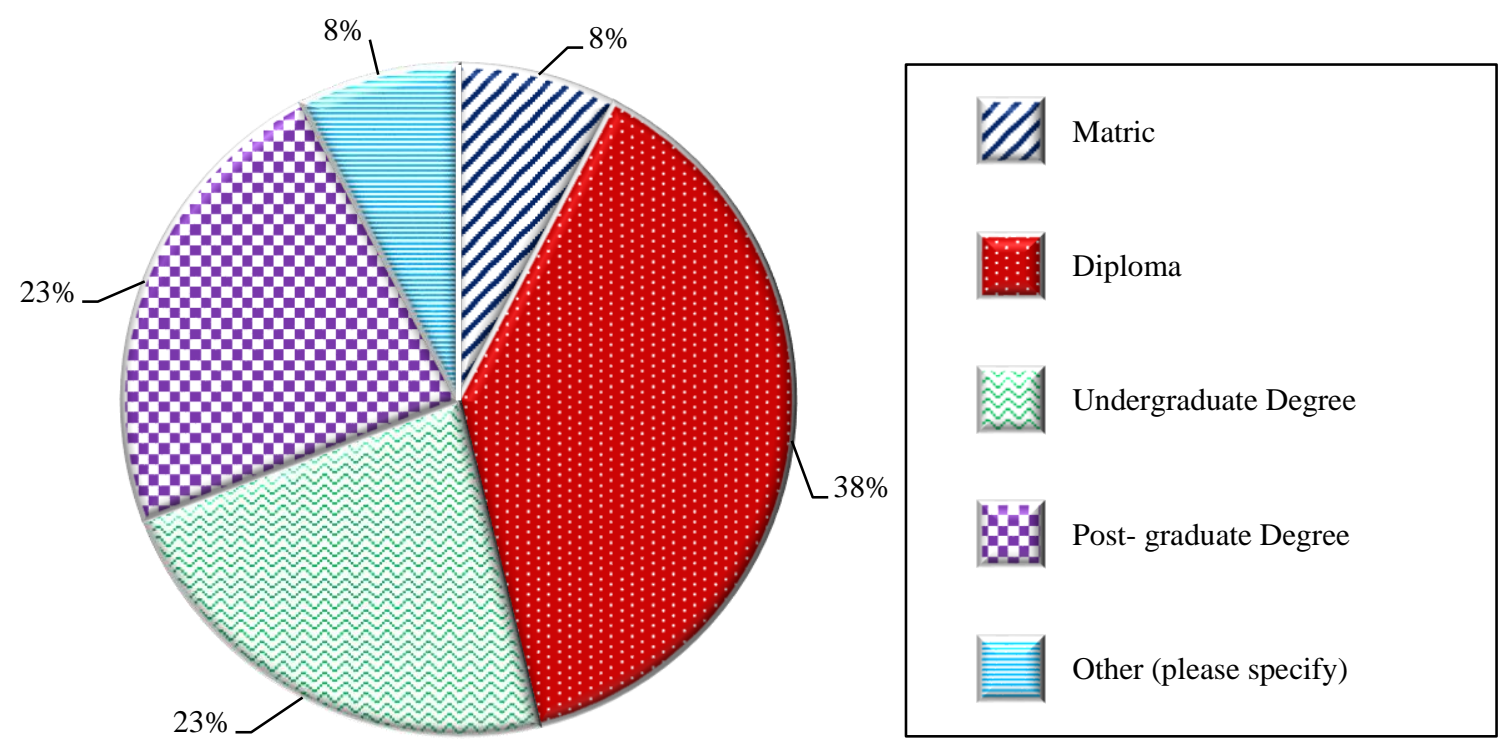

Figure 6: The education level of the respondents.

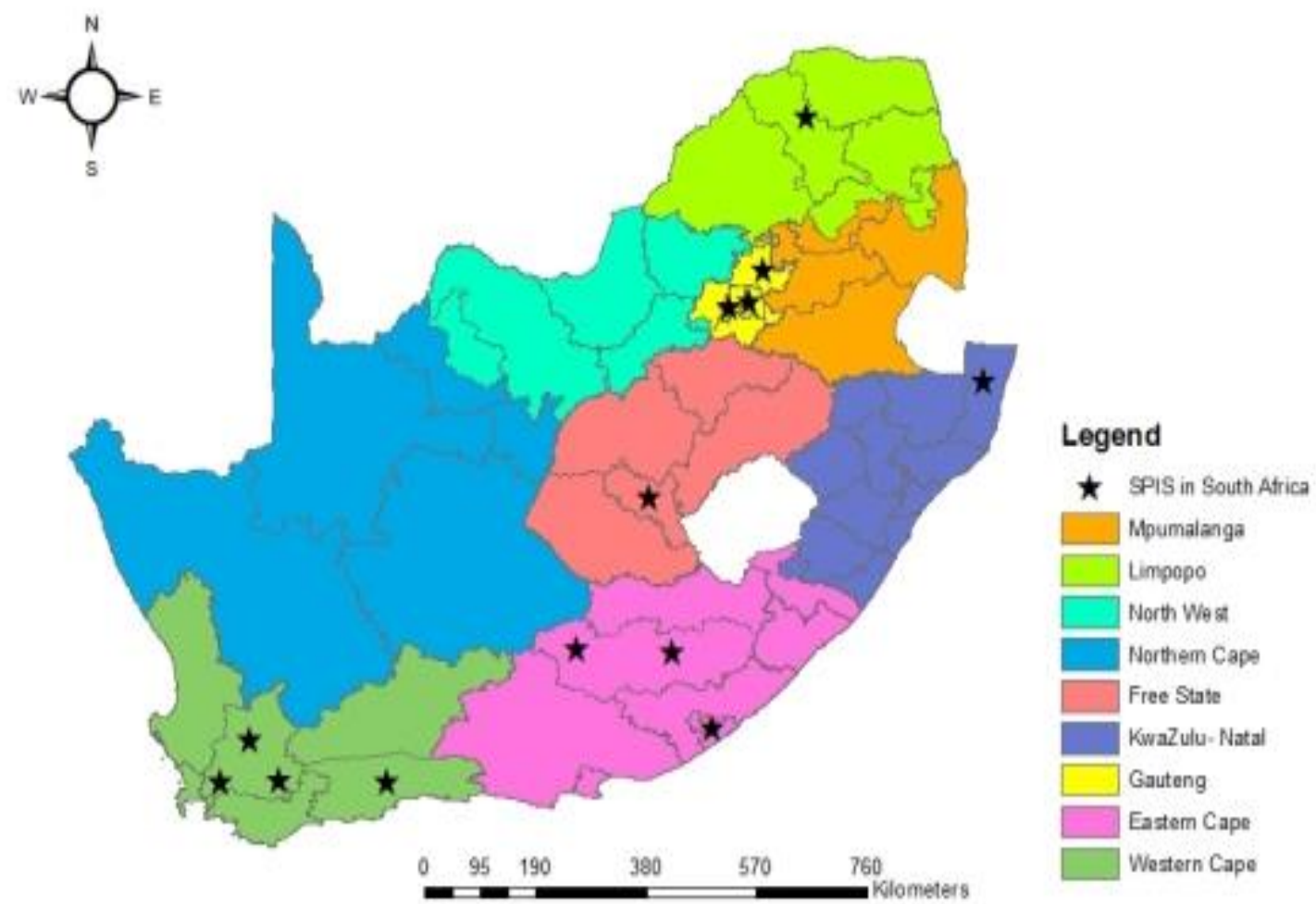

Figure 7: South African map showing the location of SPIS that were determined. 
Table 3: The province, municipalities and farm sizes of the SPIS systems

\begin{tabular}{cccc}
\hline Number of SPIS & Province & Municipality/Metropolitan & Farm size \\
(ha)
\end{tabular}

\subsubsection{Characteristics and components of the SPIS} The characteristics of each SPIS were checked to determine whether a trend existed for the SPIS users. Figures 8-12 illustrate the characteristics of the farmers' SPIS. Figure 8 shows that commercial farming is the most common type of farming integrated with SPIS. Figure 9 shows the water source that is dominantly used with SPIS by percentage is a borehole, followed by river or dam. Figure 10 shows that drip irrigation and sprinkler irrigation are equally the most integrated with SPIS. As shown in Figure 11, the type of solar panel that is used for SPIS by the respondents is mainly poly-crystalline. Figure 12 shows that most of the respondents have a submersible multistage centrifugal motor pump set pumping water.
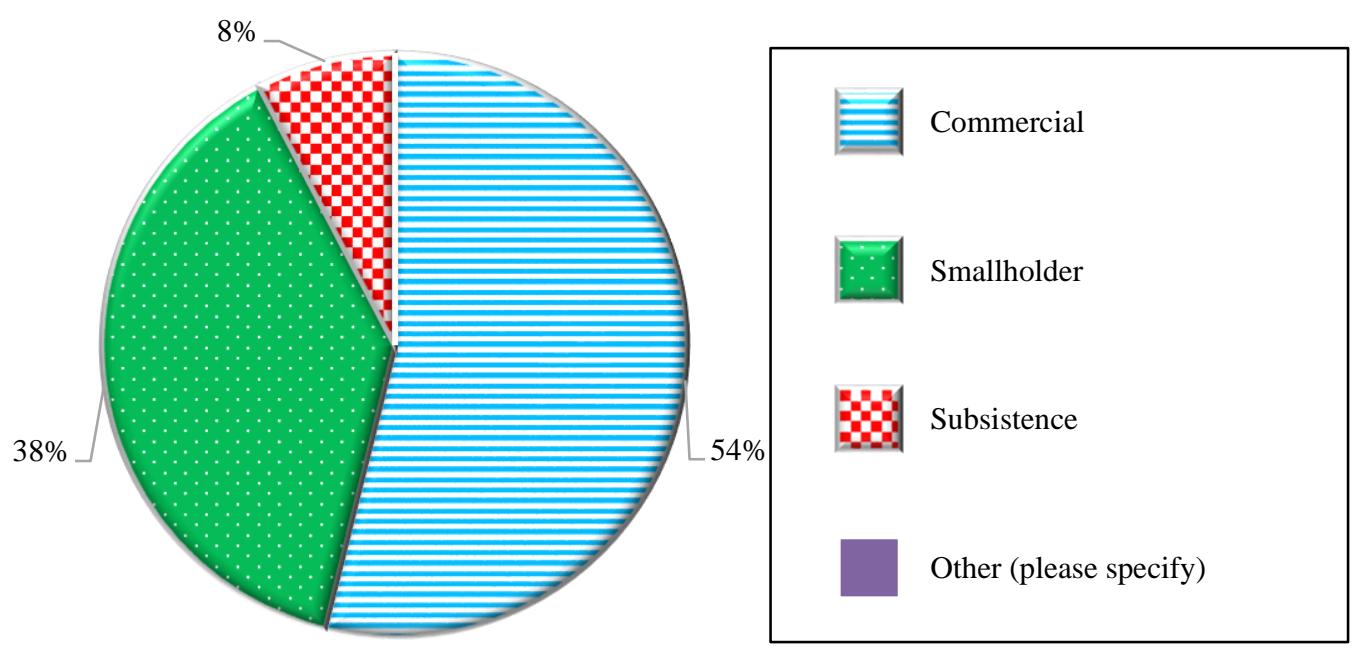

Figure 8: The type of farm the respondents' SPIS is integrated with. 

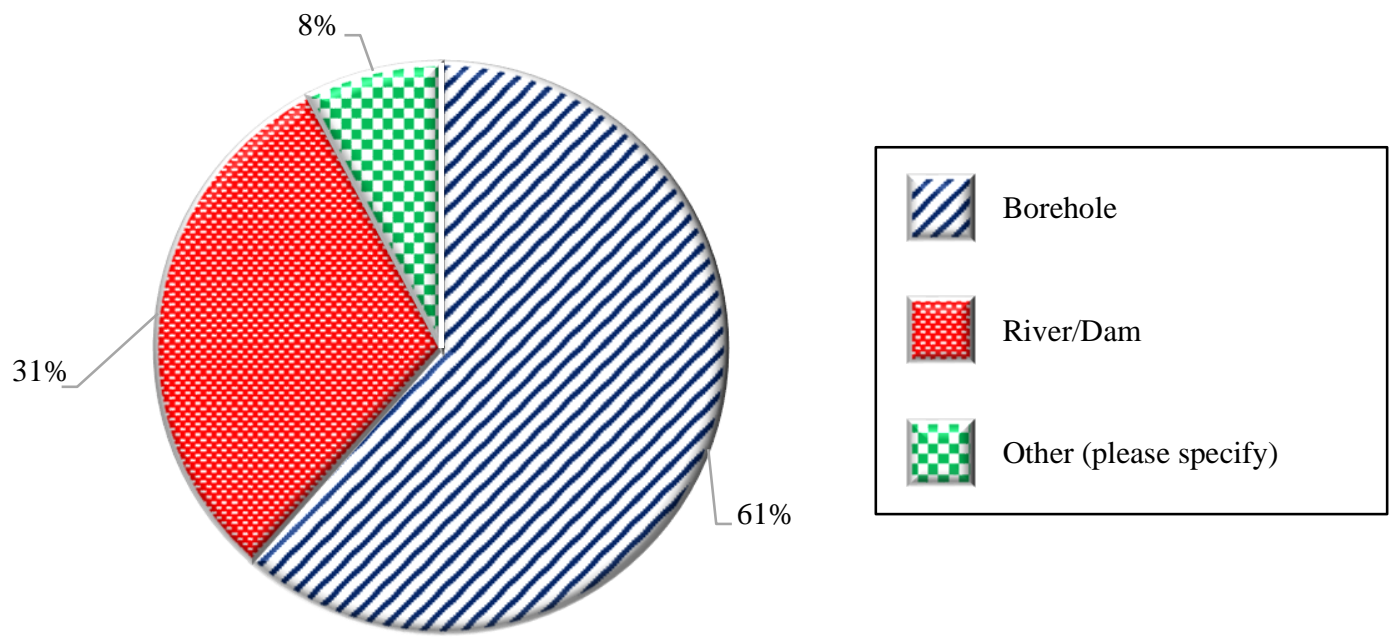

Figure 9: The type of water source for irrigation.

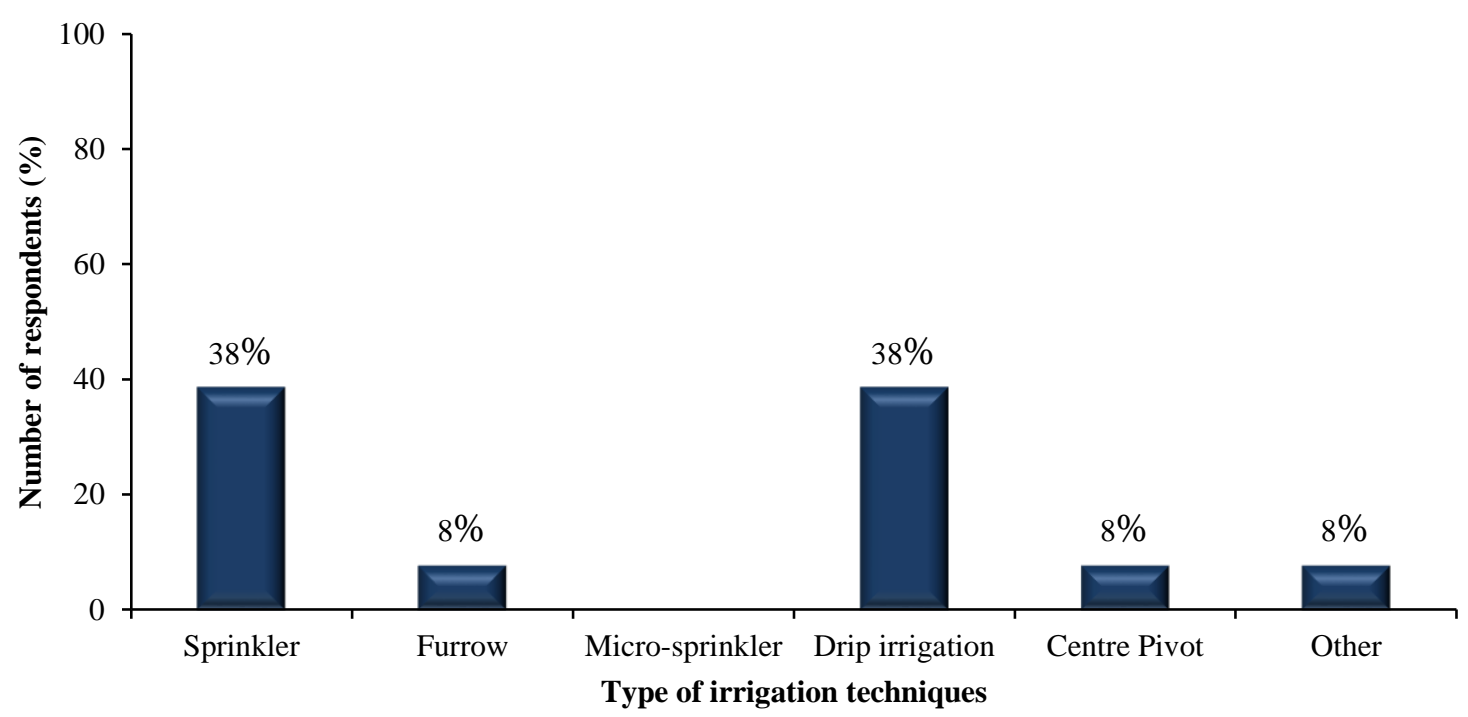

Figure 10: The type of irrigation technique SPIS is integrated with.

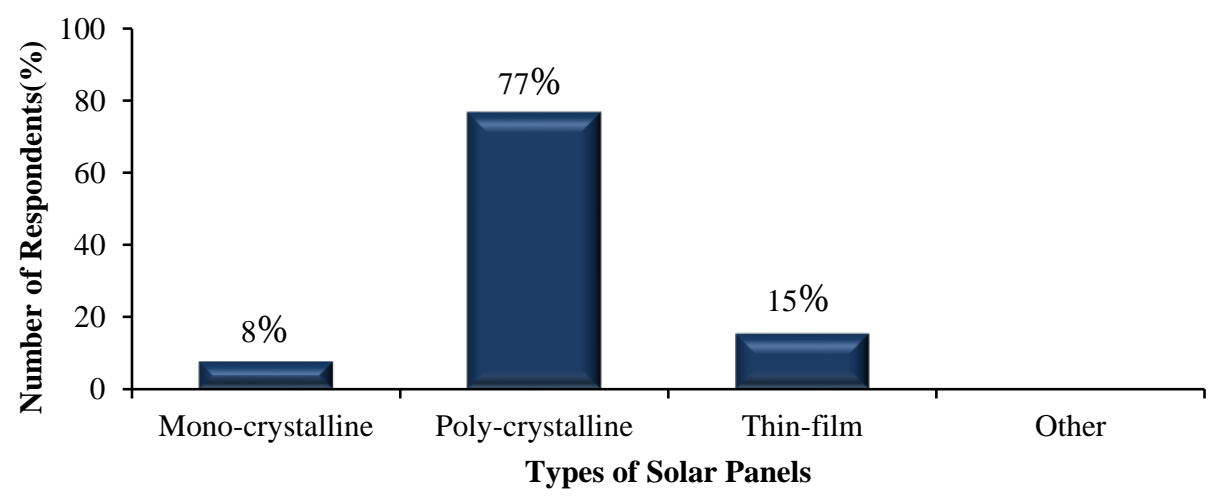

Figure 11: The type of solar panel used in the respondents' SPIS. 


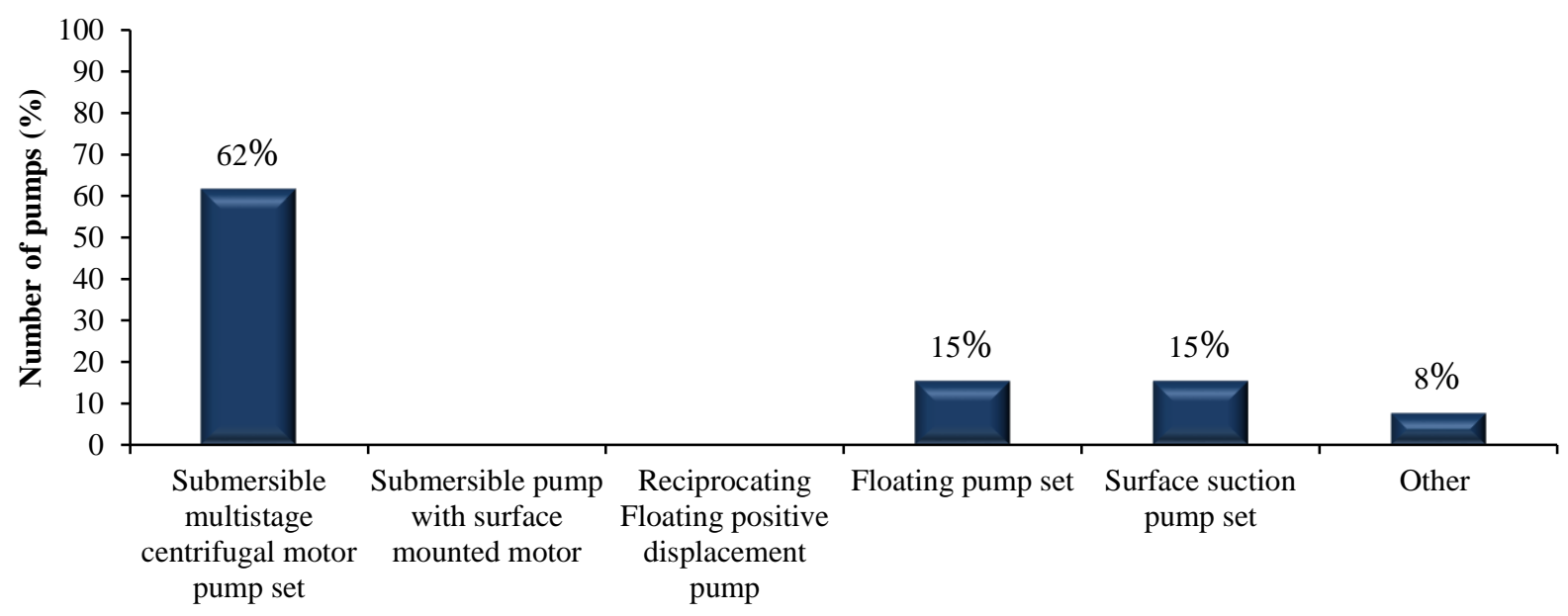

Types of motor-pumps

Figure 12: The type of pump-motor set used for the SPIS.

Table 4: Energy and potential energy storage of SPIS.

\begin{tabular}{|c|c|c|c|c|c|c|c|}
\hline & \multicolumn{2}{|c|}{ Yes } & \multicolumn{2}{|r|}{ No } & \multicolumn{2}{|c|}{ Skipped } & \multirow{2}{*}{$\begin{array}{l}\text { Total re- } \\
\text { sponses }\end{array}$} \\
\hline & No. & $\begin{array}{l}\text { Percent- } \\
\text { age (\%) }\end{array}$ & No. & $\begin{array}{l}\text { Percent- } \\
\text { age (\%) }\end{array}$ & No. & $\begin{array}{l}\text { Percent- } \\
\text { age (\%) }\end{array}$ & \\
\hline Does the system have batteries? & 1 & 8 & 12 & 92 & 0 & 0 & 13 \\
\hline $\begin{array}{l}\text { Is the system connected to the } \\
\text { grid? }\end{array}$ & 4 & 31 & 9 & 69 & 0 & 0 & 13 \\
\hline $\begin{array}{l}\text { Does the system use a generator } \\
\text { for backup power? }\end{array}$ & 3 & 23 & 9 & 69 & 1 & 8 & 13 \\
\hline $\begin{array}{l}\text { Does the system have a water tank } \\
\text { to store excess water pumped? }\end{array}$ & 4 & 31 & 9 & 69 & 0 & 0 & 13 \\
\hline $\begin{array}{l}\text { Do you ever have pressure and or } \\
\text { flow rate problems? }\end{array}$ & 4 & 31 & 9 & 69 & 0 & 1 & 13 \\
\hline
\end{tabular}

\subsubsection{Storage options (energy and water)}

The use of solar power in pumping water may need some type of water- or energy-storage option, depending on the demands of the farm. There are two possibilities for storage of excess electricity produced from the solar panels - a battery, and using the electrical grid. A storage water tank is used in a SPIS to store water that is pumped for use on days when there is not enough solar radiation to power the motor pump set. Another alternative for backup energy is a generator, which can be used when there is not enough solar irradiation available to pump water for irrigation.

Table 4 shows the responses given to five questions that required answers of yes or no. Respondents were asked if their SPIS had batteries and most responses were no. Then they were asked if their systems were connected to the electrical grid, and the dominant response was no. Asked whether a back-up generator was integrated with their SPIS, the larger number of respondents said no. The next question was if the respondents' SPIS had a storage water tank, and most responded no. Similarly, asked if respondents had pressure or flow rate problems with their SPIS, most responded no.

\subsubsection{Additional information on the SPIS}

Additional information about the SPIS's of the respondents is captured in Figures 12-15. Figure 13 shows the years in which the respondents installed their SPIS. The years 2013 and 2016 had the highest installation of SPIS. One respondent did not mention which year they implemented their SPIS.

The respondents were asked what changes they would implement to their SPIS. As Figure 14 shows, most replied that they would increase the security of their SPIS. Figure 15 shows the results for the power source the respondents were using before they installed the SPIS - most of them were using grid electricity. 


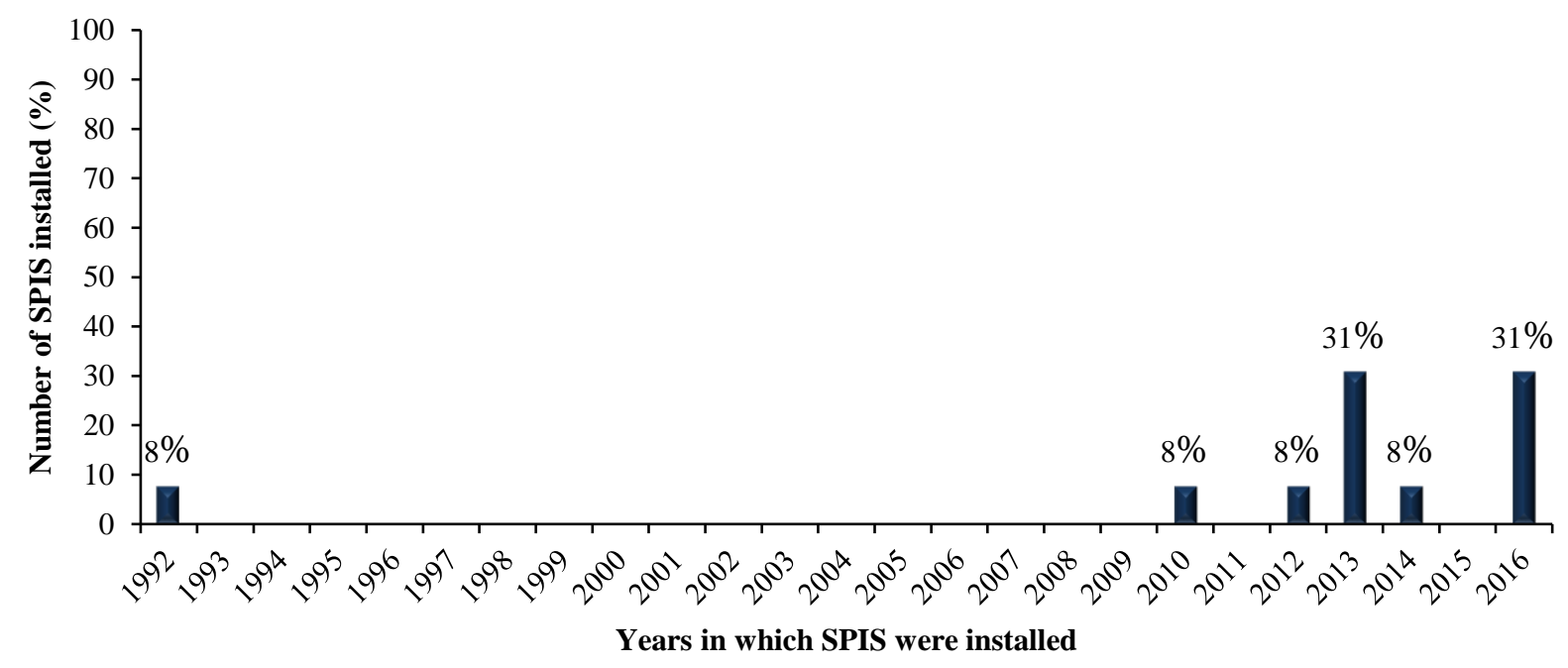

Figure 13: The year in which the SPIS was implemented.

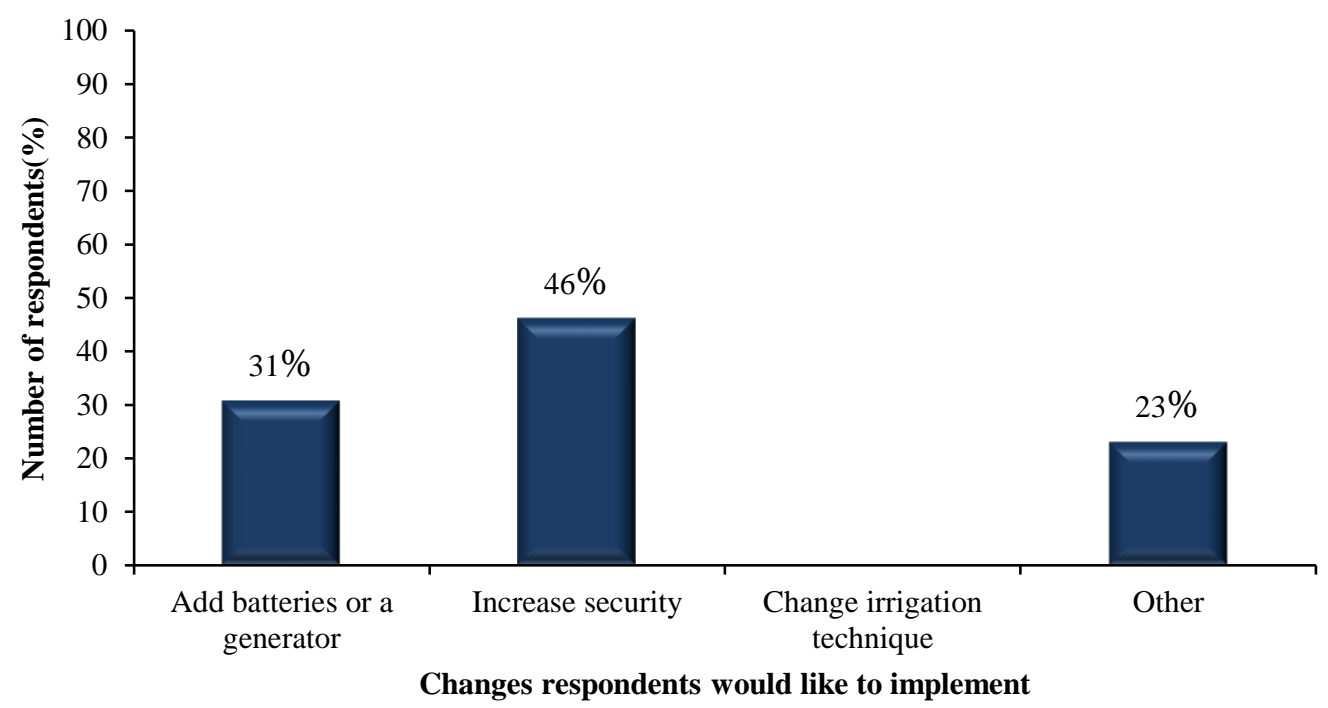

Figure 14: Improvements the respondents would implement to their SPIS.

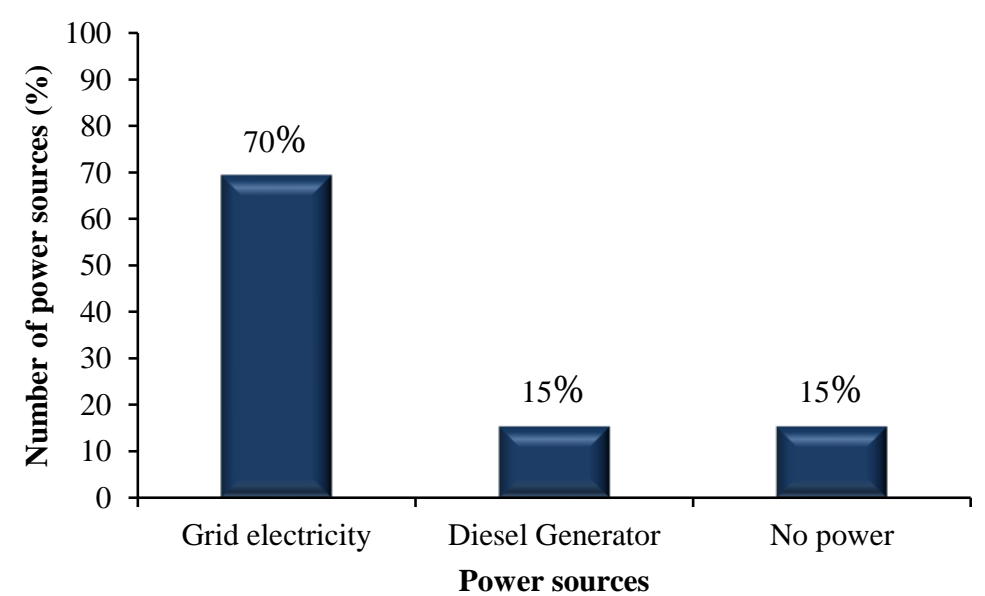

Figure 15: The power source each respondent used before the SPIS. 


\section{Discussion}

This section discusses the results obtained from the questionnaires distributed to SPIS engineers, designers and installers and SPIS users.

\subsection{SPIS engineers, designers and installers}

The discussion on the results is split into two in this subsection. The respondents' basic information, which includes the demographics and the education level and the respondents' involvement with SPIS.

\subsubsection{Respondents' basic information}

The race results correspond to the Engineering Council of South Africa's (ECSA) total number of registered engineers in 2016, where registration by race of engineers for White, African, Coloured and Indian are $71 \%, 18 \%, 9 \%$ and $2 \%$ respectively. The reason for the low registration of non-white engineers is related to individuals migrating to other economic sectors or creating their own business opportunities outside engineering (ECSA, 2016). The results for gender also correspond to ECSA's 2016 annual report, which states that $10 \%$ of registered engineers were women (ECSA, 2016; Padayachee, 2017). Gender bias is one of the main reasons stated by Padayachee. This means that fewer women than men become professional engineers. Another reason is gender imbalance, which means that the fields of science, technology, engineering and mathematics in 2016 had 23\% of women globally. Padayachee stresses that the gap needs to be addressed and prioritised so that more women can join these fields.

The education level of the SPIS engineers, installers and designers, does not correspond to the 2012 findings of the Council on Higher Education of South Africa, which state there are $41 \%$ of engineering graduates with certificates and diplomas and $44 \%$ of engineering graduates with undergraduate degrees (CHESA, 2012). The results from the survey show that many respondents have a postgraduate degree. In South Africa, the University of South Africa and the University of Pretoria offer engineering honours degrees, which are considered to be postgraduate degrees in South Africa.

\subsubsection{Respondents' involvement with SPIS}

There may be an overlap of the results, as some respondents may have come from the same company. This cannot be confirmed because the respondents answered the questionnaire anonymously. The small number of SPIS implementation around the country is mainly due to the high investment cost that comes with SPIS, as well as the perception of theft and security risk associated with them. There is also limited understanding of technology by banks for financing and the possibility of land re- form in South Africa (Hassan, 2015). In other countries, governments are promoting the use of SPIS in the framework of their national action plan regarding climate change as a way to reduce emissions in the agricultural sector (Hartung and Pluschke, 2018). South Africa has not done this yet.

According to the study by Hassan (2015), there are more than 225000 smallholder farmers in South Africa, occupying an estimated 10 million ha; over 40000 commercial farmers occupying an estimated 82 million ha; and roughly 3 million households with subsistence farmers occupying 4 million ha. Commercial farms are generally large and would require many solar panels that will require large areas of land to provide power for irrigation systems and high investment costs for the solar technology required. This explains the high number of SPIS that are implemented for smallholder irrigation systems. The high investment costs that come with SPIS would prevent subsistence farmers from implementing SPIS. Subsistence farmers grow crops for their own use to feed their families only. This would support the result of the low implementation of SPIS for subsistence farms, due to the farmers not selling their crops for profit to be able to afford SPIS. Smallholder farmers own small plots of land on which subsistence crops are grown and one or two cash crops which are sold for profit. Since the plot areas are small, the number of solar panels would be small compared to large commercial farms. Though the investment cost of SPIS is high, smallholder farmers would be able to save profit from their cash crops and/or apply for a loan to assist in purchasing a SPIS.

Singh (2016) states that the north and northwest regions of South Africa receive more solar radiation than the south and south east. Shortwave flux ( $\left(\mathrm{SW}_{\text {flux }}\right)$ is a measure of solar radiation per square area. Between 1980 and 2009, the Northern Cape received the highest mean $S W_{\text {flux }}$, followed by North West, Free State, Limpopo, Gauteng, Mpumalanga, Western Cape, Eastern Cape and Kwa-Zulu Natal. Niekerk et al. (2018) identified the irrigated area in South African provinces, and the Western Cape (269 $476 \mathrm{ha}$ ) has the highest irrigated area, followed by Limpopo (218 302 ha), Eastern Cape (152 866 ha), Northern Cape (144 579 ha), Mpumalanga (125 595ha), Kwa-Zulu Natal (177 341 ha), North West (97 211 ha), Free State (129 077 ha) and Gauteng (20 115 ha).This suggests why the Western Cape and the Eastern Cape have the highest implementation of SPIS.

The Department of Water and Sanitation in 2014 had $32 \%$ of their registered water users using sprinkler irrigation systems, followed by $29 \%$ using moving irrigation systems, then $26 \%$ using microirrigation systems, and 14\% using flood irrigation 
systems (Schulze, 2016). This explains why the respondents have primarily integrated SPIS with sprinkler and drip irrigation. According to Zegeye et al. (2014), photovoltaic energy has been widely used in low power applications in the world. A drip irrigation system requires low head compared to other irrigation systems, lowering their power requirements.

South Africa receives high levels of solar irradiation that can be converted into electrical power (DoE and GIZ, 2015). Hassan (2015) states that solar is competitive with diesel when a grid connection is not available. Many respondents feel that SPIS has potential in South Africa and they mentioned the following reasons for this:

- SPIS saves energy and has better returns if the system is subsidised.

- Grid electricity from Eskom is rising in price and is likely to become more expensive and unreliable in the future, and the economy is volatile.

- The prices of solar technology are decreasing and will continue to make it more affordable.

- With small-scale irrigation systems, SPIS has more potential.

- South Africa receives a significant amount of solar irradiation, which can be utilized with low-pressure irrigation systems

- $\quad$ SPIS save a lot of money in the long run

- South Africa receives high levels of sunshine and there are many areas that are off the grid.

The respondents that felt SPIS has no potential in South Africa gave the following reasons:

- The cost of infrastructure requirements is too high, and it is not economically viable

- Solar is not suitable for irrigation because of the varying eight hours of sunlight received daily in South Africa on average.

\subsection{SPIS users (farmers)}

The discussion on the results is split into five in this sub-section, covering the respondents' information, which includes demographics and the education level, the location information of the SPIS, the characteristics and components of SPIS, storage options and additional information of the SPIS.

\subsubsection{Basic SPIS user information}

These results are presented in Figure 6. According to the Department of Rural Development and Land Reform (2017), 72\% of South African farms and agricultural holdings are owned by white people. Males own $72 \%$ of farms and land and agricultural holdings, while females own $13 \%, 11 \%$ is Male-Female owned and $1 \%$ is co-owned. Figure 7 reflects this reality of white men dominating the ownership of farms in South Africa.

\subsubsection{Location information of SPIS}

Table 3 and Figure 7 shows that four of the 13 SPIS are in the Western Cape, three each in the Eastern Cape and Gauteng; Limpopo, KwaZulu- Natal and the Free State have one SPIS system. Figure 4 shows that engineers, installers and designers have implemented SPIS in all provinces. The survey for SPIS users did not reflect users in Mpumalanga, Northern Cape and North West. The data collected from the SPIS users and SPIS engineers, designers and installers does not correlate because the survey questionnaire did not reach as many respondents as expected. Hassan (2015) states that commercial famers in South Africa are driven toward SPIS because of energy independence and efficiency. This shows why most of the SPIS users are commercial farmers.

\subsubsection{Characteristics and components of the SPIS}

The Department of Water and Forestry (2004) stated that South Africa primarily uses surface water for most of its urban, industrial and irrigation requirements. Groundwater is also used, but mainly in rural areas and more arid areas. Groundwater use is limited to a few places in the country due to the geology that is hard rock. This information does not correspond to the results obtained in the survey as most of the SPIS use boreholes as a water source.

Most of the respondents have sprinkler and drip irrigation systems. One of the benefits of having these two irrigation techniques integrated with solar power is that, compared to furrow and centre pivot irrigation, the power requirements of these systems are low head, meaning lower pumping costs (Basalike, 2015).

The most commonly used type of solar panel for SPIS is poly-crystalline solar panels. These results correspond to the literature, where the cost factor of mono-crystalline solar panels overrules its advantage with its efficiency, which ranges between 15-20\%, while the efficiency of polycrystalline solar panels ranges between 13-16\% (Bharam, 2012; Davies, 2013). The cost of poly-crystalline solar panels is less than the cost of mono-crystalline solar panels (Davies, 2013). Thin-film solar panels are the cheapest type of solar panel, but the reason why this type of solar panel is seldom used is because their efficiency is lower, at 7-13\%, which means they require more space (Davies, 2013; Sendy, 2017).

\subsubsection{Storage options (energy and water)}

The submersible centrifugal pump has a high reliability for pumping water, especially for boreholes with medium depth (60 m) (Argaw, 2003). The submersible multistage centrifugal pump can provide high head pumping requirements (Volk, 2005). 
Most of the respondents are pumping water from a borehole and most of the respondents are using submersible multistage centrifugal pumps with their SPIS.

There are disadvantages to using a battery pack in a SPIS, including a reduction in the efficiency of the overall system, because the operating voltage is dictated by the batteries and not the solar panels. Batteries are not recommended, because of the additional cost for maintenance and initial cost of the system (Eker, 2005). This explains why only a few SPIS users have SPIS with a battery pack. The reason there are few grid-connected SPIS is that Eskom does not allow the connection of small-scale generator connections to their low voltage networks because this places the safety of the public and Eskom's operating staff at risk (Eskom, 2014). Biswas and Iqbal (2018) state that the use of a diesel engine provides lower costs for hybrid systems, but they are a bad solution for longer periods of time due to increasing fuel prices and pollution of the environment. According to Abdelfattah (2017), a stand-alone system with an elevated storage water tank is the most popular. This is not reflected in the results, as only $36 \%$ of the respondents have storage water tanks integrated with their SPIS.

The design of SPIS needs to be fit-for-purpose and needs regular services to advise farmers on the most suitable system, but these are often not in place (Hartung and Pluschke, 2018). This is the cause of some systems having low pressure and flow rates at times.

\subsubsection{Additional information on the SPIS}

Eskom resorted to national 'load shedding' from late 2007 to protect the power system from a total black out, and a national emergency was declared in January 2008. Load shedding continued until the end of March 2008, while Eskom initiated a recovery plan, with the support of the government and business' (Joffe, 2012). This would explain the high implementation of SPIS during 2010 and 2016 as most of the respondents switched from Eskom grid electricity to solar power.

SPIS is vulnerable to theft and vandalism in some areas in South Africa (Makana Municipality, 2005; Hartung and Pluschke, 2018). The problem of theft and vandalism is why many of the SPIS users specified increasing the security of their SPIS. This also explains why some SPIS engineers, designers and installers have had some of the SPIS they been involved with vandalised.

\section{Conclusion and recommendations}

This study concludes that there is SPIS in South Africa, and a significant amount is located in the Western Cape and the Eastern Cape, but the other provinces do also have SPIS. The main reason most of the SPIS users opted to use solar as a power source for their water pumping needs was to get off the electrical grid and have some energy independence. This was due to the increase in electrical power costs and unreliable electricity supply during the years South Africa experienced load shedding. This can also be seen by the fact that most SPIS users installed their SPIS from 2010 to 2016. It was also found during this study that solar powered irrigation has potential in South Africa, as most of the SPIS users that participated in the questionnaire are commercial farmers.

The solar panel type that is predominantly used is poly-crystalline solar panels, because of its high efficiency (13-16\%) compared to thin-film solar panels (7-13\%), and its lower cost than mono-crystalline solar panels. Sprinkler and drip irrigation are the techniques that are mainly integrated with solar powered irrigation by the SPIS users that participated in the questionnaire. These two irrigation systems are predominant in South Africa, so it is important that funders and policy makers target them for solar power integration. The motor-pump set that is primarily used by the SPIS users is the submersible multistage centrifugal motor-pump set. These types of pumps are high head low flow types of pumps, where they can be used to pump water from deep surface water and boreholes. Most of the SPIS users pump their water from boreholes. This information helps the designers and installers with proper sizing and integration of appropriate solar panels according to the water source.

Overall, the information acquired gave an idea of the extent of SPIS in South Africa and the main characteristics of SPIS in South Africa.

The recommendations going forward with this study are to find a better way to obtain responses from the SPIS users that were not identified. This can be done by visiting SPIS engineers, installers and designers directly and asking them for the details of the SPIS they implemented, and possibly also giving the contact information of the SPIS users. Some companies are restricted from doing this, however. It is recommended that a detailed study be conducted to establish the feasibility of SPIS development in South Africa.

\section{Authors contributions}

P. Piliso: Conceptualisation, investigation, data collection, data analysis, drafting and development of the manuscript.

A. Senzanje: Conceptualisation, project supervision and writing - review and editing.

K. Dhavu: Funding acquisition, project supervision and writing - review and editing.

\section{Acknowledgements}

The authors thank the Water Research Commission for financial support to conduct the research. 


\section{References}

Abdelfattah, A. 2017. Solar powered water lifting for irrigation. Food and Agriculture Organization of the United Nations, Rome, Italy.

Argaw, N. 2003. Renewable energy for water pumping applications in rural villages. National Renewable Energy Laboratory, Colorado, USA.

Basalike, P. 2015. Design, optimization and economic analysis of photovoltaic water pumping technologies, case Rwanda. Unpublished thesis, School of Business, Society and Engineering, Mälardalen University, Västerås, Sweden.

Bharam, V. 2012. Solar energy: Materials for photovolaic cell advantages and challenges for silicon in the photovoltaic cells. Trinity College, Connecticut, USA.

Biswas, S and Iqbal, M. 2018. Dynamic modelling of solar water pumping system with energy storage. Journal of Solar Energy 1 (1): 1-12. doi: 10.1155/2018/8471715

Bonthuys, J. 2018. In-depth study shed light on irrigated farming areas, water use. [Internet] The Water Wheel. Available from: http://www.wrc.org.za/wp-content/uploads/mdocs/WW\%20July_Aug\%202018\%20IRRIGATION\%20WATER\%20USE.pdf. [Accessed: 04 May 20201].

CHESA [Council of Higher Education South Africa].2012. Vital Stats Public Higher Education 2012 [Internet]. Available from: https://www.che.ac.za/\#/docview. [Accessed: 25 September 2018].

Cornish, G. 1998. Modern irrigation technologies for smallholders in developing countries. Intermediate Technology Publications in association with HR Wallingford UK.

Davies, S. 2013. Solar panel types. Solarflex SA, Somerset West, South Africa.

DoE [Department of Energy]. 2012. Draft 2012 integrated energy planning report. Department of Energy, Pretoria, South Africa.

DoE [Department of Energy] and GIZ [Deutsche Gesellschaft für Internationale Zusammenarbeit]. 2015. State of renewable energy in South Africa. Department of Energy, Pretoria, South Africa.

Department of Rural Development and Land Reform. 2017. Land audit report: Phase II: Private land ownership by race, gender and nationality. Department of Rural Development and Land Reform, Pretoria, South Africa.

DWF [Department of Water Affairs and Forestry]. 2004. National water resource strategy. Department of Water Affairs and Forestry, Pretoria, South Africa.

ECSA [Engineering Council of South Africa]. 2016. Engineering Council of South Africa annual report 2015/2016. Engineering Council of South Africa, Waterview Corner Building e Ernest Oppenheimer Avenue Bruma 2198, South Africa.

Eker, B. 2005. Solar powered water pumping systems. Trakia Journal of Sciences 3 (7): 7-11.

Erasmus, D. 2013. Solar energy use on the rise in SA. [Internet]. Farmer's Weekly. Available from: https://www.farmersweekly.co.za/agri-technology/farming-for-tomorrow/solar-energy-use-on-the-rise-in-sa. [Accessed: 05 October 2018].

Eskom. 2014. Connection of small-scale renewable generation to Eskom's network. [Internet]. Eskom. Available from: http://www.eskom.co.za/Whatweredoing/Documents/CustBulletinLPU.pdf\#page=1\&zoom=auto,-19,325. [Accessed:30 September 2018].

Gomo,T. 2010. Assessing the performance of smallholder irrigation in South Africa and opportunities for deriving best management practices. Thesis, School of Bioresources Engineering and Environmental Hydrology, University of KwaZulu-Natal, Pietermaritzburg, South Africa.

Hartung, H and Pluschke, L. 2018. The benefits and risks of solar-powered irrigation - A global overview. Food and Agricultural Organization of the United Nations, Rome, Italy.

Hassan, M. 2015. Market assessments for solar-powered irrigation pumps in Morocco, South Africa and Yemen. International Finance Corporation, Rome, Italy.

Joffe, H. 2012. Challenges for South Africa's electricity supply industry. The Journal of the Helen Suzman Foundation (64): 32-37.

Jumman, A and Lecler, N. 2010. Electricity tariff increases impact on irrigators. Proceedings of the South African Sugar Technology Association (83): 152-155.

Laswell, R. 2018. Comparing monocrystalline, polycrystalline, and thin-film solar panels. [Internet]. Semprius. Available from: https://www.semprius.com/comparing-mono-polycrystalline-and-thin-film-solar-panels/. [Accessed: 10 October 2018].

Niekerk, A, Jarmain, C, Goudriaan, R, Muller, S, Ferreira, F, Münch, Z, Pauw, T, Stephenson, G and Gibson, L. 2018. An earth observation approach towards mapping irrigated areas and quantifying water use by irrigated crops in South Africa. Report No. TT 745/17. Water Research Commission, Gezina, South Africa.

Padayachee, P. 2017. We have too few women engineers in South Africa - Here's what we can do to fix that. [Internet]. Huffington Post. Available from: https://www.huffingtonpost.co.za/priyanka-padayachee/we-have-too-fewwomen-engineers-in-south-africa_a_21703682/. [Accessed: 25 September 2018].

Makana Municipality. 2005. Local Environmental Action Plan. Part III Comprehensive Audit Report: Domestic energy, solar power and waste management. Makana Municipality, South Africa. 
Schulze, RE. 2016. On observations, climate challenges, the South African agriculture sector and considerations for an adaptation handbook. In: Schulze, R.E.(ed), Handbook for farmers, officials and other stakeholders on adaptation to climate change in the agriculture sector within South Africa. Ch Section A: Agriculture and climate change in South Africa: Setting the scene, Chapter A1.

Sendy, A. 2017. Pros and cons of monocrystalline vs polycrystalline solar panels. [Internet]. Solar Reviews. Available from: https://www.solarreviews.com/blog/pros-and-cons-of-monocrystalline-vs-polycrystalline-solar-panels. [Accessed: 25 September 2018].

Singh, J. 2016. Ranking South African provinces on the basis of MERRA 2D surface incident shortwave flux. Journal of Energy in Southern Africa 27 (3): 50-57. doi: 10.17159/2413-3051/2016/v27i3a1555

SurveyMonkey. 1999. Survey Monkey. [Internet]. Available from: https://www.surveymonkey.com/. [Accessed: 30 August 2018].

Van der Walt, J. 2019. Western Cape boasts Africa's first floating solar system. [Internet]. Farmers Weekly. Available from: https://www.farmersweekly.co.za/agri-news/south-africa/western-cape-boasts-africas-first-floating-solarsystem/. [Accessed: 12 May 2019].

Volk, M. 2005. Pump characteristics and applications. Taylor and Francis Group, Boca Raton, Florida, USA.

Zegeye, M, Tadiwos, T and Aman, A. 2014. Optimal sizing of solar water pumping system for small scale irrigation: Case study of Dangila. International Journal of Renewable and Sustainable Energy 3 (5): 99-107. doi: $10.11648 /$ j.ijrse.20140305.13 